\title{
The association between daily total physical activity and risk of cardiovascular disease among hypertensive patients: a 10- year prospective cohort study in China
}

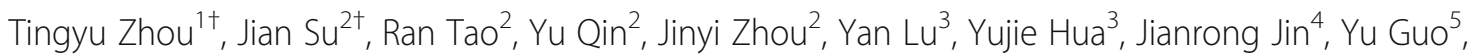
Zhengming Chen ${ }^{6}$, Liming $\mathrm{Li}^{7}$ and Ming $\mathrm{Wu}^{1 *}$

\begin{abstract}
Background: The effect of high levels of physical activity and relationship between daily total physical activity and the risk of cardiovascular disease (CVD) among hypertensive people were not clear. This study aimed to explore the optimum level of physical activity for CVD prevention.

Methods: Data used in the present study was derived from the sub-study of China Kadoorie Biobank study (CKB) in Jiangsu province of China. The CKB was a prospective cohort study established during 2004-2008. At baseline, 53,259 participants aged 35-74 years were recruited for the CKB Jiangsu sub-study conducted in Wuzhong district of Suzhou City. Among those 53,259 participants, the 20,179 hypertensive individuals were our study population. The outcome events were cardiovascular diseases (CVDs), while the independent variable was total daily physical activity. The Cox proportional hazard models were introduced to investigate the association between total physical activity and CVDs, reporting as hazard ratios (HR) and 95\% confidence intervals (Cls).

Results: During a 10.1-year follow-up, 2419 CVD cases were identified. After adjustment for potential confounding factors, compared with participants at the lowest level of daily total physical activity, the hazard ratios for CVDs were 0.87 (95\%Cl: 0.79-0.97), 0.73 (95\%Cl: 0.65-0.83) and 0.75 (95\%Cl: 0.65-0.85) for participants within 2, 3 and 4 quartiles of physical activity. Such a negative association between total physical activity and CVDs were also observed among participants by gender and age-group, but within patients with stage 1 hypertension only. Moreover, the association of physical activity with CVDs was U-shape and the lowest HR $(0.63,95 \% \mathrm{Cl}: 0.54-0.74)$ was observed at $35.4 \mathrm{MET}$-h/d of total physical activity.

Conclusions: Total daily physical activity was negatively associated with CVDs among hypertensive adults in China, and this association was U-shape. It has some public health implications that community-based total physical activity intervention campaigns can be of help for CVDs prevention among hypertensive people in China.
\end{abstract}

Keywords: China, Physical activity, Hypertension, Cardiovascular disease

\footnotetext{
* Correspondence: jswuming@vip.sina.com

${ }^{\dagger}$ Tingyu Zhou and Jian Su contributed equally to this work.

'Department of Epidemiology and Biostatistics, School of Public Health,

Nanjing Medical University, Nanjing 211166, China

Full list of author information is available at the end of the article
}

(c) The Author(s). 2021 Open Access This article is licensed under a Creative Commons Attribution 4.0 International License, which permits use, sharing, adaptation, distribution and reproduction in any medium or format, as long as you give appropriate credit to the original author(s) and the source, provide a link to the Creative Commons licence, and indicate if changes were made. The images or other third party material in this article are included in the article's Creative Commons licence, unless indicated otherwise in a credit line to the material. If material is not included in the article's Creative Commons licence and your intended use is not permitted by statutory regulation or exceeds the permitted use, you will need to obtain permission directly from the copyright holder. To view a copy of this licence, visit http://creativecommons.org/licenses/by/4.0/ The Creative Commons Public Domain Dedication waiver (http://creativecommons.org/publicdomain/zero/1.0/) applies to the data made available in this article, unless otherwise stated in a credit line to the data. 


\section{Introduction}

The number of adults with hypertension has tripled during the past 40 years in low- and middle-income countries [1]. In China, a large nationwide representative survey reported that $23.2 \%$ of Chinese adults had hypertension in 2012-2015 [2], while uncontrolled blood pressure (BP) among hypertensive patients was found to contribute to approximately one-third death of cardiovascular diseases (CVDs) [3]. Hypertensive patients are at a higher risk of experiencing CVD events and appear to experience CVD events about 5 years earlier than their counterparts with blood pressure under control [4].

The hypertension-induced CVD death may be prevented through improving physical activity (PA), as evidence show that PA can reduce the risk of hypertension $[5,6]$. PA can provide a wide range of favorable response in cardiovascular system such as improving the dynamics of cardiovascular system and reducing the prevalence of coronary heart disease and cardiomyopathy [7]. One study conducted by O'Donovan et al. reported that compared with physically inactive participants, the hazard ratio (HR) for CVD mortality was 0.59 (95\% CI: $0.48-0.73$ ) for regularly active participants [8]. Despite the repeated evidence on the inverse association between PA and mortality risk of CVD in general population [9], such an association among hypertensive patients remains scarce.

The 2018 European Society of Cardiology/Hypertension $(\mathrm{ESC} / \mathrm{ESH})$ guidelines for the arterial hypertension recommended regular aerobic exercise, at least 30-min of moderate dynamic aerobic exercise for $5-7$ days per week, i.e., at least $150 \mathrm{~min} /$ week [10], while physical activity was generally not recommended for hypertensive persons with very high BP (i.e., BP $>180 / 110 \mathrm{mmHg}$ ) [11]. At meantime, hypertensive people appear to be less physically active than those without hypertension [12]. It is reported that only about one third of hypertensive patients achieve the recommended PA level [13]. Most previous researches subdivided physical activity by domains (e.g., occupational, domestic and leisure-time activity) [14] or intensities (e.g., light, moderate and vigorous physical activities) when exploring the relationship between PA and CVDs [15]. However, in developing countries including China, residents engaged in physical activity with occupational and domestic activity as the majority but very few PA at leisure time [16]. Therefore, daily total physical activity might better reflect the level of physical activity compared with selected domains or intensities of physical activity for people in developing societies. To bridge this gap, we used data from a 10-year prospective cohort study in China to examine the relationship between daily total physical activity and reduced risk of cardiovascular diseases among hypertensive individuals in China.

\section{Methods}

\section{Study design and participants}

The data used in this study were derived from the China Kadoorie Biobank (CKB) study in Wuzhong district of Suzhou city, Jiangsu Province. Details of the study design, survey methods, and participant characteristics have been reported elsewhere previously $[17,18]$. CKB study was conducted in 10 geographically defined regions (5 urban and 5 rural) in China, and Wuzhong district of Suzhou is one of the five urban regions. Between June 2004 and July 2008, 53,259 of permanent residents aged 35-74 years with no severe disability were recruited for the baseline survey. Subsequently, participants were followed up for morbidity and mortality every year. By January 14 of 2017 , there were 2934 death and 476 (< 1\%) participants lost to follow-up.

In the present study, we included subjects with prevalent hypertension at baseline. Prevalent hypertensive individuals were defined as those: (a) with measured systolic BP (SBP) $\geq 140 \mathrm{mmHg}$, and/or measured diastolic BP (DBP) $\geq 90 \mathrm{mmHg}$, or (b) having been previously diagnosed as hypertensive patients by registered physicians, or (c) using antihypertensives [3]. Initially, 21,124 participants with hypertension were successfully recruited. Among them, 945 individuals were not included in our analysis as they had been diagnosed with CVDs, e.g., stroke, heart disease, or cancer at baseline and thus 20,179 hypertensive participants were included in the present study.

\section{Ascertainment of outcomes}

The information on incidence of CVD was regularly collected through Disease Surveillance Points (DSP) system death registry, chronic disease registry, national health insurance system, health insurance databases and annual active follow-up [17]. Each CVD event was ascertained by scanned copies of medical records, original disease reporting card or official death certificates [19]. There was a city-wide investigation on under-reporting rate of death cases in disease surveillance system every 3 years in Suzhou to assess the under-reporting of death cases, and the under-reporting rates were $<5 \%$ in Suzhou in the past 10 years [20]. Fatal and nonfatal events were coded using the International Classification of Disease, Tenth Revision (ICD-10) by trained staff "blinded" to baseline exposures. The primary outcome events were occurring ischemic heart disease (IHD) (I20-25) and cerebrovascular diseases (I60-I69). In the analysis, participants were classified as having or not having CVDs during the follow-up period.

\section{Physical activity measurements}

At baseline survey, the information on physical activity included frequency, intensity, and time spent on 
occupational tasks, commuting, leisure time activities and household tasks during the past year. Occupational tasks refer to the physical activity performed during paid employment, while commuting PA means the physical activity performed during travel to and from daily work. The time spent on leisure-sedentary activities such as watching television, playing cards and reading was defined as leisure-sedentary time. The questions used to measure physical activity were adapted from validated instruments used in previous studies [21, 22]. Those adapted PA question items were then integrated into a questionnaire specifically for assessing physical activity in CKB study [23], although it was not validated as a survey instrument.

For all the four PA domains, a specific metabolic equivalent (MET) was assigned to each PA type. Metabolic equivalents of each PA type were adopted from the 2011 Compendium of Physical Activities [24]. The sum of all the METs/day was defined as the total daily PA in this study. And then participants were quartiled into four sub-groups for analysis: Q1 (<11.20 MET-h/d), Q2 (11.20-19.99 MET-h/d), Q3 (20.00-34.71 MET-h/d) and Q4 (> $34.71 \mathrm{MET}-\mathrm{h} / \mathrm{d})$.

\section{BP measurements}

All participants were asked to remain at rest in a seated position for at least $5 \mathrm{~min}$ before BP measurement. Additionally, smokers were required not to smoke for at least $15 \mathrm{~min}$. BP was measured twice using a UA-779 digital monitor on unclothed right upper arm. If the variation of SBP between two measurements differed by $>10 \mathrm{mmHg}$, a third measurement would be taken and the last two measurements were recorded. We used the mean of the two BP readings in the analysis.

The BP-levels were classified according to Chinese Guidelines for Prevention and Treatment of Hypertension using records of on-site measurement at baseline survey [25]. For those hypertensive individuals, they were classified as having BP under control, if they had $\mathrm{SBP}<140 \mathrm{mmHg}$ and DBP $<90 \mathrm{mmHg}$. Definitions of other BP-levels for hypertensive participants are presented below:

1. Stage 1 hypertension: SBP between 140 and 159 $\mathrm{mmHg}$ or DBP between 90 and $99 \mathrm{mmHg}$.

2. Stage 2 hypertension: SBP between 160 and 179 $\mathrm{mmHg}$ or DBP between 100 and $109 \mathrm{mmHg}$.

3. Stage 3 hypertension: SBP $\geq 180 \mathrm{mmHg}$ or DBP $\geq 110 \mathrm{mmHg}$.

\section{Covariates measurements}

The survey was conducted via face-to-face interview by trained health workers using a laptop-based questionnaire. Information on covariates included sociodemographic characteristics (age, gender, levels of education etc), lifestyle behaviors (smoking status, alcohol consumption, intakes of red meat and fresh fruit etc), personal health and medical history (hypertension and diabetes).

Smoking status and alcohol consumption were classified as current smoker/weekly drinker or not in this study. Current smokers were defined as those who reported having ever smoked one or more cigarettes (or their equivalent) daily for at least 6 months [26]. Current drinkers were specified as those who had drunk alcohol at least once a week during the previous 12 months [27]. Measurements of weight, height, waist and hip circumferences were conducted at interview. Body mass index (BMI) was calculated as $\mathrm{BMI}=($ body weight in kilograms) $/$ (height (in meters $)^{2}$ ). Diabetes mellitus was defined as a selfreported of physician diagnosis or screen-detected diabetes [28]. Screen-detected diabetes was defined as no prior history of diabetes with either non-fasting blood glucose $\geq 11.1 \mathrm{mmol} / \mathrm{L}$ or fasting blood glucose $\geq 7.0 \mathrm{mmol} / \mathrm{L}$ [29].

\section{Statistical analysis}

Summary statistics of demographics were reported as mean \pm standard deviation for numerical variables. Continuous variables were compared by one-way analysis of variance and using Welch's ANOVA when variances were unequal. Categorical variables were compared by Pearson's $X^{2}$ test between different levels of physical activity groups. Person-years at risk were calculated from the recruitment date at baseline to the date of death, loss to follow-up, or censoring date, whichever came first. The Cox proportional hazard models were used to identify the association between levels of total physical activity and incidence of CVD [30] by hazard ratio (HR) and 95\% confidence interval (CI). Covariates adjusted for in multivariable models included age at baseline (4 groups), gender (male or female), smoking status (current smoker or not), alcohol consumption (current weekly drinker or not), intake frequencies of red meat and fresh fruit $(<4$ times per week or $\geq 4$ times per week), prevalent diabetes at baseline (presence or absence), leisure-sedentary time (continuous) and BP-levels (4 groups) [31]. Sensitivity analyses excluded participants who had IHD and cerebrovascular diseases during the first year were conducted in the study.

Linear relationship between daily total physical activity and CVD risk was assessed using restricted cubic spline functions [15] with three knots located at the 5th, 50th, and 95th percentiles of physical activity. SAS 9.4 (SAS Institute, Cary, NC) and STATA 13.0 (Stata Corp, College Station, TX, USA) were used for the statistical analyses. All statistical tests were 2-tailed and $P$ value less than 0.05 was regarded as significant. 


\section{Results}

\section{Baseline characteristics of participants}

Among the 20,179 participants at baseline, their mean age was $56.3 \pm 9.8$ years, and $44.3 \%$ were men. And, those who reported higher levels of total physical activity tended to be younger, more likely to be male, with less diabetes and lower SBP level (Table 1). There were very few people $(0.8 \%)$ people lost to follow-up. During 211, 066 person-years of follow-up, there were 2419 patients of CVD observed in this study, including 1672 people with cerebrovascular disease, 584 individuals with IHD, and 163 participants simultaneously with cerebrovascular disease and IHD.

In general, levels of total physical activity (mean [SD]) among men were higher than women (25.7 [16.4] vs 21.2 [13.8] MET-h/d, $P<0.01$ ), while men had higher occupational physical activity (19.9 [16.3] vs 11.2 [14.0] MET-h/d, $P<0.01$ ), but less household activity (3.4 [3.1] vs 8.5 [5.2] MET-h/d, $P<0.01)$ than women. The level of physical activity engaged in leisure-time activity among men was higher than that among women $(0.8$ [2.1] vs 0.5 [1.7] $\mathrm{MET}-\mathrm{h} / \mathrm{d}, P<0.01)$.

\section{Association of total physical activity with risk of CVD}

Table 2 presents the association of total daily PA and the risk of developing CVDs among overall and genderstratified participants in this study. Total physical activity levels were inversely associated with the risk of CVDs. Compared with hypertensive patients in the lowest quartile of physical activity, the hazard ratios (95\%CIs) after adjustment for potential confounding factors were $0.87(0.79-0.97), 0.73(0.65-0.83)$ and 0.75 (0.65-0.85) for those in quartile 2,3 and 4, respectively. After stratified by gender, the significant relationship between PA and CVDs were still examined among men and women, with one exception that the association between Q2 PA and CVDs among women was not significant. Moreover, the similar scenarios were also observed for participants within different age-groups (Table 3).

Table 4 shows the associations of PA with CVDs among participants with different BP levels. Interestingly, the significant associations of PA with CVDs were identified only among stage 1 hypertensive patients, showing a reduction of CVD risk of $22 \%, 41 \%$ and $34 \%$ for participants within quartile 2, 3 and 4, respectively, compared to those with BP under-control. Moreover, participants with stage 3 hypertension within Q3 PA sub-group were less likely to develop CVDs $(H R=0.67$, 95\%CI: 0.49-0.96) relative to their counterparts within Q1 category. We also took a look at the PA-CVDs associations within participants who had self-reported hypertension and newly-detected hypertension, separately. The scenarios were similar to those examined among overall participants (Additional file 1: Appendix 1).

Further, we classified individuals into three categories according to the latest WHO guidelines on physical activity: insufficient physical activity (group 1), meet the weekly physical activity recommendation (group 2) and

Table 1 Selected characteristics of participants by the quartiles of physical activity in this study

\begin{tabular}{|c|c|c|c|c|c|c|}
\hline \multirow[t]{2}{*}{ Characteristics } & \multirow[b]{2}{*}{$N=20,179$} & \multicolumn{4}{|c|}{ Physical activity } & \multirow[b]{2}{*}{$P$ value } \\
\hline & & $\begin{array}{l}\text { Q1 } \\
n=4919\end{array}$ & $\begin{array}{l}\text { Q2 } \\
n=5166\end{array}$ & $\begin{array}{l}\text { Q3 } \\
n=5046\end{array}$ & $\begin{array}{l}\mathrm{Q} 4 \\
n=5048\end{array}$ & \\
\hline Age. y & $56.3 \pm 9.8$ & $62.2 \pm 8.9$ & $57.4 \pm 9.4$ & $53.8 \pm 9.1$ & $51.7 \pm 8.4$ & $<0.001^{*}$ \\
\hline Male, No. (\%) & $8941(44.3)$ & $2106(42.8)$ & $1733(33.6)$ & $2145(42.5)$ & $2957(58.6)$ & $<0.001^{*}$ \\
\hline Treated with antihypertension, No. (\%) & $8134(40.3)$ & $2460(50.0)$ & $2264(43.8)$ & $1820(36.1)$ & $1590(31.5)$ & $<0.001^{*}$ \\
\hline Diabetes mellitus, No. (\%) & $1690(8.4)$ & $562(11.4)$ & $489(9.5)$ & $359(7.1)$ & $280(5.6)$ & $<0.001^{*}$ \\
\hline $\mathrm{SBP}, \mathrm{mmHg}$ & $150.9 \pm 18.1$ & $151.6 \pm 19.1$ & $151.2 \pm 18.6$ & $151.1 \pm 18.1$ & $149.5 \pm 16.6$ & $<0.001^{*}$ \\
\hline $\mathrm{DBP}, \mathrm{mmHg}$ & $86.3 \pm 9.9$ & $84.4 \pm 10.3$ & $85.6 \pm 9.9$ & $87.3 \pm 9.7$ & $87.9 \pm 9.5$ & $<0.001^{*}$ \\
\hline $\mathrm{BMI}, \mathrm{Kg} / \mathrm{m}^{2}$ & $25.0 \pm 3.3$ & $24.8 \pm 3.4$ & $25.2 \pm 3.3$ & $25.1 \pm 3.3$ & $25.0 \pm 3.1$ & 0.088 \\
\hline Resting heart rate, bpm & $80.8 \pm 13.1$ & $80.6 \pm 13.1$ & $80.9 \pm 13.1$ & $80.9 \pm 13.3$ & $80.7 \pm 13.0$ & 0.385 \\
\hline Leisure-sedentary time, h/d & $3.1 \pm 2.2$ & $3.8 \pm 2.9$ & $3.3 \pm 2.2$ & $2.7 \pm 1.6$ & $2.4 \pm 1.4$ & $<0.001^{*}$ \\
\hline Current smoker, No. (\%) & $5745(28.5)$ & $1151(23.4)$ & $1109(21.5)$ & $1447(28.7)$ & $2038(40.4)$ & $<0.001^{*}$ \\
\hline Current weekly drinker, No. (\%) & 3938 (19.5) & $733(14.9)$ & $766(14.8)$ & $979(19.4)$ & $1460(28.9)$ & $<0.001^{*}$ \\
\hline Education, No. (\%) & & & & & & $<0.001^{*}$ \\
\hline$\leq 6 y$ & $14,149(70.1)$ & $3758(76.4)$ & $3536(68.5)$ & 3472 (68.8) & $3383(67.0)$ & \\
\hline $7-9 y$ & $4270(21.2)$ & 710 (14.4) & 1018 (19.7) & 1168 (23.2) & $1374(27.2)$ & \\
\hline $10-12 y$ & $1364(6.7)$ & $316(6.5)$ & $446(8.6)$ & $334(6.6)$ & $268(5.3)$ & \\
\hline$\geq 13 y$ & $396(2.0)$ & $135(2.7)$ & $166(3.2)$ & $72(1.4)$ & $23(0.5)$ & \\
\hline
\end{tabular}

(1) Mean and standard deviation, unless specified otherwise

(2) $* P<0.05$ 
Table 2 Hazard ratios (95\% Cl) of CVD across quartiles of total physical activity for all participants and stratified by gender in this study

\begin{tabular}{|c|c|c|c|c|c|c|c|c|}
\hline Physical activity & $\begin{array}{l}\text { No. of } \\
\text { Observations }\end{array}$ & $\begin{array}{l}\text { No. of } \\
\text { Cases }\end{array}$ & $\begin{array}{l}\text { Person years } \\
\text { of follow-up }\end{array}$ & $\begin{array}{l}\text { Incidence } \\
\text { density }(1 / 1000 \\
\text { person-years })\end{array}$ & $\begin{array}{l}\text { Model } 1 \\
\text { Hazard ratio } \\
(95 \% \mathrm{Cl})\end{array}$ & $P$ value & $\begin{array}{l}\text { Model } 2 \\
\text { Hazard ratio } \\
(95 \% \mathrm{Cl})\end{array}$ & $P$ value \\
\hline All & 20,179 & 2419 & 211,066 & 11.46 & & & & \\
\hline Q1 & 4919 & 943 & 50,392 & 18.71 & 1.00 & & 1.00 & \\
\hline Q2 & 5166 & 651 & 54,255 & 12.00 & $0.86(0.78-0.96)$ & $0.005^{*}$ & $0.87(0.79-0.97)$ & $0.009^{*}$ \\
\hline Q3 & 5046 & 439 & 53,535 & 8.20 & $0.72(0.64-0.81)$ & $<0.001^{*}$ & $0.73(0.65-0.83)$ & $<0.001^{*}$ \\
\hline Q4 & 5048 & 386 & 52,884 & 7.30 & $0.72(0.63-0.82)$ & $<0.001^{*}$ & $0.75(0.65-0.85)$ & $<0.001^{*}$ \\
\hline Male & 8941 & 1135 & 91,136 & 12.45 & & & & \\
\hline Q1 & 2106 & 452 & 20,758 & 21.77 & 1.00 & & 1.00 & \\
\hline Q2 & 1733 & 218 & 17,780 & 12.26 & $0.82(0.69-0.96)$ & $0.016^{*}$ & $0.82(0.69-0.97)$ & $0.017^{*}$ \\
\hline Q3 & 2145 & 200 & 22,133 & 9.04 & $0.70(0.59-0.84)$ & $<0.001^{*}$ & $0.70(0.58-0.83)$ & $<0.001^{*}$ \\
\hline Q4 & 2957 & 265 & 30,465 & 8.70 & $0.72(0.61-0.85)$ & $<0.001^{*}$ & $0.73(0.61-0.87)$ & $<0.001^{*}$ \\
\hline Female & 11,238 & 1284 & 119,930 & 10.71 & & & & \\
\hline Q1 & 2813 & 491 & 29,634 & 16.57 & 1.00 & & 1.00 & \\
\hline Q2 & 3433 & 433 & 36,475 & 11.87 & $0.89(0.78-1.02)$ & 0.086 & $0.91(0.80-1.04)$ & 0.153 \\
\hline Q3 & 2901 & 239 & 31,402 & 7.61 & $0.73(0.63-0.86)$ & $<0.001^{*}$ & $0.76(0.65-0.90)$ & $0.001^{*}$ \\
\hline Q4 & 2091 & 121 & 22,419 & 5.40 & $0.70(0.57-0.86)$ & $<0.001^{*}$ & $0.75(0.60-0.93)$ & $0.008^{*}$ \\
\hline
\end{tabular}

Model 1 was adjusted for age and gender

Model 2 was additionally adjusted for smoking status, alcohol consumption, intake frequencies of red meat, intake frequencies of fresh fruit, prevalent diabetes at baseline, leisure-sedentary time and BP-levels

* $P<0.05$

exceed the recommendations of the guidelines (group 3) [32]. Only those participants who met the physical activity recommendation had the lowest risk of CVD $(\mathrm{HR}=$ 0.80, 95\%CI: 0.69-0.92) (Additional file 1: Appendix 2). The associations of total physical activity and risk of CVD did not change substantially in sensitivity analyses with exclusion of participants who had CVD during the first year of follow-up (Additional file 1: Appendix 3-5).

Figure 1 displays the linear relations between daily total physical activity level and CVDs. Cubic spline graphs revealed a U-shape relationship between PA and CVDs among participants, although PA was negatively associated with CVDs in this study. When participants had a total daily PA of $35.4 \mathrm{MET}-\mathrm{h} / \mathrm{d}$, they were at the lowest risk of experiencing CVDs $(\mathrm{HR}=0.63,95 \% \mathrm{CI}$ : 0.54-0.74).

\section{Discussion}

In this prospective population-based study among Chinese hypertensive adults, we aimed to examine the association of total daily PA and the risk of developing CVDs. We found that being physically active was significantly associated with a reduced risk of CVDs, and such a significant association between PA and CVDs was mainly among patients with stage 1 hypertension. Moreover, the association between total physical activity level and CVD risk was U-shape, suggesting that an optimal
PA level existed for prevention of CVDs among hypertensive adults.

To date, several studies have evaluated the beneficial impact of sufficient physical activity on hypertensive individuals $[33,34]$. Fan et al. reported that high level of physical activity group had a 35\% risk reduction of death from CVD among Chinese population [31]. And one study conducted among 18,794 Danish hypertensive people showed that moderate/ high level of physical activity might prevent participants from CVD-induced death with a dose-response relationship [11]. The findings in our study were in line with those documented in the previous literature $[11,31,33,34]$. The interesting finding that a Ushape relationship between PA and CVDs was also similar to that reported in a study conducted among Japanese population [35]. In this Japanese study, a $\mathrm{U}$ - or J-shape association of PA with hemorrhage stroke and a L-shape association with ischemic stroke were identified [35]. This might be, at least partially, explained by that high-intensity physical activity can cause a short-lasting and sudden increase in BP [36] and lead to temporary physiological pressure [37].

A recent meta-analysis showed that 4000-7999 MET-minutes per week, equivalent to 10-19 MET-h/ d, could substantially reduce the risk of IHD (23\%) [38]. Another meta-analysis included 36 studies 
Table 3 Hazard ratios (95\% Cl) of CVD across quartiles of total physical activity stratified by age in this study

\begin{tabular}{|c|c|c|c|c|c|c|c|c|}
\hline & No. of Observations & No. of Cases & $\begin{array}{l}\text { Person years } \\
\text { of follow-up }\end{array}$ & $\begin{array}{l}\text { Incidence density } \\
\text { ( } 1 / 1000 \text { person-years) }\end{array}$ & $\begin{array}{l}\text { Model } 1 \\
\text { Hazard ratio } \\
(95 \% \mathrm{Cl})\end{array}$ & $P$ value & $\begin{array}{l}\text { Model } 2 \\
\text { Hazard ratio } \\
(95 \% \mathrm{Cl})\end{array}$ & $P$ value \\
\hline \multicolumn{9}{|c|}{ Age (years) } \\
\hline$<50$ & 5038 & 181 & 53,207 & 3.40 & & & & \\
\hline Q1 & 464 & 30 & 4976 & 6.03 & 1.00 & & 1.00 & \\
\hline Q2 & 1005 & 34 & 10,574 & 3.22 & $0.53(0.33-0.87)$ & $0.012^{*}$ & $0.58(0.35-0.97)$ & $0.037^{*}$ \\
\hline Q3 & 1580 & 46 & 16,701 & 2.75 & $0.46(0.29-0.72)$ & $<0.001^{*}$ & $0.51(0.31-0.82)$ & $0.006^{*}$ \\
\hline Q4 & 1989 & 71 & 20,956 & 3.39 & $0.56(0.37-0.86)$ & $0.008^{*}$ & $0.63(0.40-1.00)$ & 0.051 \\
\hline $50-$ & 7365 & 579 & 78,045 & 7.42 & & & & \\
\hline Q1 & 1188 & 114 & 12,693 & 8.98 & 1.00 & & 1.00 & \\
\hline Q2 & 1971 & 164 & 21,016 & 7.80 & $0.87(0.69-1.11)$ & 0.260 & $0.91(0.72-1.16)$ & 0.440 \\
\hline Q3 & 2084 & 140 & 22,157 & 6.32 & $0.67(0.52-0.86)$ & $0.001^{*}$ & $0.70(0.54-0.91)$ & $0.007^{*}$ \\
\hline Q4 & 2122 & 161 & 22,179 & 7.26 & $0.72(0.56-0.92)$ & $0.008^{*}$ & $0.79(0.61-1.02)$ & 0.071 \\
\hline $60-$ & 5666 & 1027 & 59,177 & 17.35 & & & & \\
\hline Q1 & 2081 & 429 & 21,372 & 20.07 & 1.00 & & 1.00 & \\
\hline Q2 & 1600 & 272 & 16,770 & 16.22 & $0.82(0.70-0.96)$ & $0.012^{*}$ & $0.83(0.71-0.96)$ & $0.015^{*}$ \\
\hline Q3 & 1143 & 196 & 12,274 & 15.97 & $0.78(0.66-0.92)$ & $0.004^{*}$ & $0.78(0.66-0.93)$ & $0.006^{*}$ \\
\hline Q4 & 842 & 130 & 8761 & 14.84 & $0.67(0.55-0.82)$ & $<0.001^{*}$ & $0.69(0.56-0.85)$ & $<0.001^{*}$ \\
\hline$\geq 70$ & 2110 & 632 & 20,637 & 30.62 & & & & \\
\hline Q1 & 1186 & 370 & 11,351 & 32.60 & 1.00 & & 1.00 & \\
\hline Q2 & 590 & 181 & 5895 & 30.70 & $0.96(0.80-1.15)$ & 0.674 & $0.97(0.81-1.16)$ & 0.712 \\
\hline Q3 & 239 & 57 & 2403 & 23.72 & $0.71(0.54-0.94)$ & $0.016^{*}$ & $0.70(0.53-0.93)$ & $0.014^{*}$ \\
\hline Q4 & 95 & 24 & 988 & 24.29 & $0.70(0.47-1.07)$ & 0.097 & $0.71(0.47-1.09)$ & 0.115 \\
\hline
\end{tabular}

Model 1 was adjusted for gender

Model 2 was additionally adjusted for smoking status, alcohol consumption, intake frequencies of red meat, intake frequencies of fresh fruit, prevalent diabetes at baseline, leisure-sedentary time and BP-levels

* $P<0.05$

reported that the greatest reduction of CVD risk was observed from inactive to moderate physical activity [39]. In our study, the optimal effect of PA on CVDs was observed at 35.4 MET-h/d, however participants could get the major benefit of total physical activity on CVDs with 7-25 MET-h/d.

Physical activity was documented as one of the influencing factors of and cornerstone therapies for reducing risk of CVD in patients with hypertension [40]. The mechanisms might involve the exerciseinduced cardiovascular benefits, which prevent agerelated decrements in arterial compliance and function [41]. Regular exercise might be able to reduce circulate markers of systemic inflammation [42], improve calcium handling through the sarcoendoplasmic reticulum calcium transport ATPase [43] and reduce the production of reactive oxygen species in mitochondrial [44].

\section{Strengths and limitations}

The present study has several strengths. First, the data used in this study was from a 10-yearfollow-up prospective cohort study, suggesting the association between physical activity and CVDs was of a causal nature. Second, total physical activity, not selected PA domains, was used to predict participants' PA level. Third, the classical potential confounding factors of CVDs were adjusted for in the analysis.

Meanwhile, there are some limitations deserved attention for the interpretation of our study finding. First, only physician-diagnosed CVDs were defined as the outcome events. If CVD patients had mild symptoms but were not recorded in hospitalization registry, they might be not classified as outcome case. This may lead to an underestimation of the PA-CVDs association. Second, the question items used to assess physical activity were adapted from validated instruments and integrated into a PA questionnaire, however this integrated $\mathrm{PA}$ questionnaire was not specifically validated for CKB study. Third, information on physical activity was self-reported, which may imply potential recall bias. Fourth, the baseline information on physical activity was used as independent variable. Over the 10-yearfollow-up period, participants PA level might different from that at baseline. 
Table 4 Hazard ratios $(95 \% \mathrm{Cl})$ of CVD across quartiles of total physical activity stratified by BP-levels in this study

\begin{tabular}{|c|c|c|c|c|c|c|c|c|}
\hline & $\begin{array}{l}\text { No. of } \\
\text { Observations }\end{array}$ & No. of Cases & $\begin{array}{l}\text { Person years } \\
\text { of follow-up }\end{array}$ & $\begin{array}{l}\text { Incidence density } \\
(1 / 1000 \text { person-years) }\end{array}$ & $\begin{array}{l}\text { Model } 1 \\
\text { Hazard ratio } \\
(95 \% \mathrm{Cl})\end{array}$ & $P$ value & $\begin{array}{l}\text { Model } 2 \\
\text { Hazard ratio } \\
(95 \% \mathrm{Cl})\end{array}$ & $P$ value \\
\hline BP under control & 3141 & 406 & 32,394 & 12.53 & & & & \\
\hline Q1 & 912 & 167 & 9235 & 18.08 & 1.00 & & 1.00 & \\
\hline Q2 & 853 & 116 & 8873 & 13.07 & $1.01(0.79-1.29)$ & 0.927 & $1.04(0.81-1.33)$ & 0.759 \\
\hline Q3 & 690 & 66 & 7217 & 9.15 & $0.86(0.64-1.16)$ & 0.321 & $0.88(0.65-1.19)$ & 0.410 \\
\hline Q4 & 686 & 57 & 7069 & 8.06 & $0.80(0.58-1.10)$ & 0.170 & $0.82(0.59-1.15)$ & 0.253 \\
\hline Stage 1 hypertension & 11,508 & 1106 & 121,101 & 9.13 & & & & \\
\hline Q1 & 2536 & 437 & 26,195 & 16.68 & 1.00 & & 1.00 & \\
\hline Q2 & 2857 & 290 & 30,126 & 9.63 & $0.77(0.67-0.90)$ & $<0.001^{*}$ & $0.78(0.67-0.91)$ & $0.001^{*}$ \\
\hline Q3 & 2969 & 185 & 31,634 & 5.85 & $0.58(0.48-0.69)$ & $<0.001^{*}$ & $0.59(0.49-0.71)$ & $<0.001^{*}$ \\
\hline Q4 & 3146 & 194 & 33,146 & 5.85 & $0.64(0.53-0.77)$ & $<0.001^{*}$ & $0.66(0.55-0.80)$ & $<0.001^{*}$ \\
\hline Stage 2 hypertension & 4048 & 594 & 42,272 & 14.05 & & & & \\
\hline Q1 & 1057 & 214 & 10,833 & 19.75 & 1.00 & & 1.00 & \\
\hline Q2 & 1051 & 164 & 11,009 & 14.90 & $0.99(0.81-1.22)$ & 0.938 & $1.00(0.81-1.23)$ & 0.974 \\
\hline Q3 & 1015 & 131 & 10,777 & 12.16 & $0.98(0.78-1.23)$ & 0.864 & $1.01(0.80-1.27)$ & 0.957 \\
\hline Q4 & 925 & 85 & 9653 & 8.81 & $0.79(0.60-1.04)$ & 0.095 & $0.83(0.62-1.10)$ & 0.192 \\
\hline Stage 3 hypertension & 1482 & 313 & 15,299 & 20.46 & & & & \\
\hline Q1 & 414 & 125 & 4129 & 30.27 & 1.00 & & 1.00 & \\
\hline Q2 & 405 & 81 & 4247 & 19.07 & $0.79(0.59-1.05)$ & 0.106 & $0.80(0.60-1.07)$ & 0.129 \\
\hline Q3 & 372 & 57 & 3907 & 14.59 & $0.65(0.47-0.91)$ & $0.011^{*}$ & $0.67(0.49-0.96)$ & $0.027^{*}$ \\
\hline Q4 & 291 & 50 & 3016 & 16.58 & $0.87(0.60-1.25)$ & 0.442 & $0.89(0.61-1.30)$ & 0.552 \\
\hline
\end{tabular}

Model 1 was adjusted for age and gender

Model 2 was additionally adjusted for smoking status, alcohol consumption, intake frequencies of red meat, intake frequencies of fresh fruit, prevalent diabetes at baseline and leisure-sedentary time

* $P<0.05$

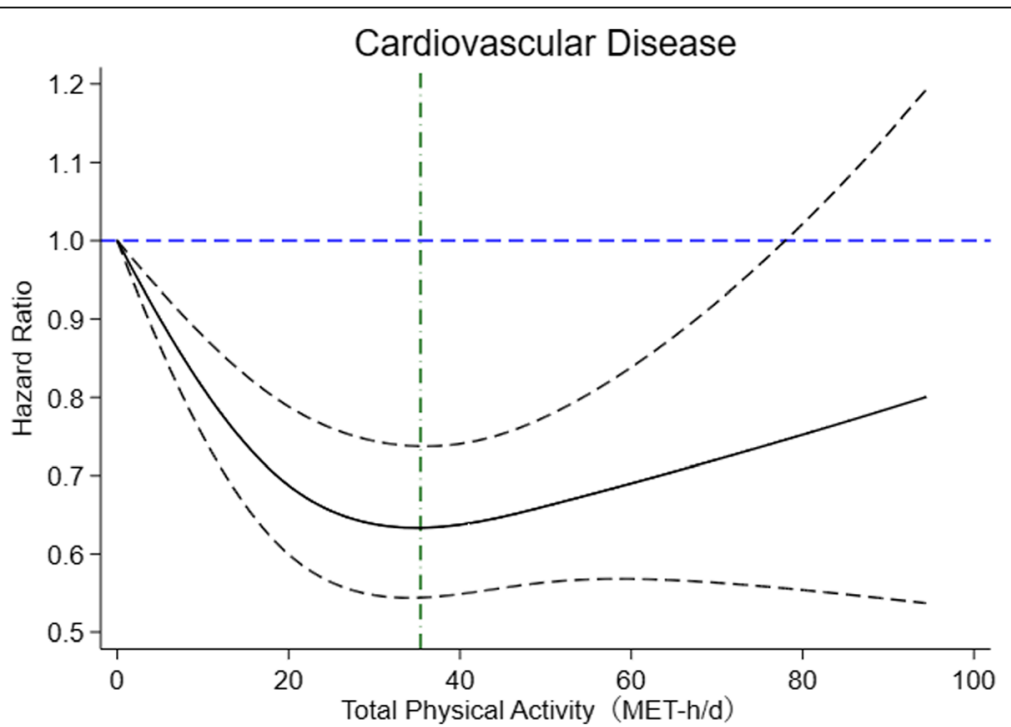

Fig. 1 Restricted cubic spline model of hazard ration of CVD with total physical activity. Adjust for gender, age, smoking status, alcohol consumption, intake frequencies of red meat, intake frequencies of fresh fruit, prevalent diabetes at baseline, leisure-sedentary time and BP-levels. The dashed lines represent the $95 \%$ confidence intervals 
Therefore, the findings from our study should be interpreted prudently.

\section{Conclusions}

In conclusion, there is a significant negative association between total daily physical activity and CVDs and such a negative association was U-shape among hypertensive patients in China. It has some public health implications that community-based total physical activity intervention campaigns can be of help for CVDs prevention among hypertensive people in China.

\section{Supplementary Information}

The online version contains supplementary material available at https://doi. org/10.1186/s12889-021-10551-z.

Additional file 1 : Appendix 1. Hazard ratios (95\%Cl) of CVD across quartiles of total physical activity stratified by BP-levels with self-reported and new detected hypertension. Appendix 2. Hazard ratios (95\% Cl) of CVD across physical activity categorized by recommendation of guidelines. Appendix 3. Hazard ratios $(95 \% \mathrm{Cl})$ of CVD across quartiles of total physical activity for all participants and stratified by gender with sensitivity analyses. Appendix 4. Hazard ratios $(95 \% \mathrm{Cl})$ of CVD across quartiles of total physical activity stratified by age with sensitivity analyses. Appendix 5. Hazard ratios $(95 \% \mathrm{Cl})$ of CVD across quartiles of total physical activity stratified by BP-levels with sensitivity analyses. Appendix 6. Basic characteristics of respondent, non-respondent, death population of Respondent and respondents die of CVD at baseline.

\section{Acknowledgements}

The authors thank Chinese Center for Disease Control and Prevention and Jiangsu provincial Health Administrative Departments. The most important acknowledgement is to the participants in the study and the members of the survey teams, as well as to the project development and management teams based at Beijing and Oxford.

\section{Authors' contributions}

T.Y.Z. and J.S. designed the research. T.Y.Z. did the data analyses and drafted the manuscript. J.S. revised the data analysis. R.T., Y.Q., J.Y.Z. and M.W. revised the manuscript critically for important intellectual content. Y.L., Y.J.H., J.R.J., Y.G. Z.M.C. and L.M.L. edited and proofread the manuscript. All authors read and approved the final manuscript.

\section{Funding}

This work was supported by National Key Research and Development Program of China (grands 2016YFC0900500, 2016YFC0900501). The CKB baseline survey and the first resurvey were supported by a grant from the Kadoorie Charitable Foundation in Hong Kong. The long-termfollow-up is supported by grants from the UK Wellcome Trust (202922/Z/16/Z, 088158/Z/ 09/Z, 104085/Z/14/Z). The funders had no role in the study design, data collection, data analysis and interpretation, writing of the report, or the decision to submit the article for publication.

\section{Availability of data and materials}

The data that support the findings of this study are available from Department of China Kadoorie Biobank but restrictions apply to the availability of these data, which were used under license for the current study, and so are not publicly available. Data are however available from the authors upon reasonable request and with permission of Department of China Kadoorie Biobank

\section{Declarations}

\section{Ethics approval and consent to participate}

The study was approved by Ethical Review Committee of the Chinese Center for Disease Control and Prevention (Beijing, China) and the Oxford (UK).
Written informed consent was obtained from all participants. All methods were performed in accordance with the relevant guidelines and regulations.

\section{Consent for publication}

Not applicable.

\section{Competing interests}

The author declares no competing interests.

\section{Author details}

${ }^{1}$ Department of Epidemiology and Biostatistics, School of Public Health, Nanjing Medical University, Nanjing 211166, China. ${ }^{2}$ Department of Non-communicable Chronic Disease Control and Prevention, Jiangsu Provincial Center for Disease Control and Prevention, Nanjing 210009, China. ${ }^{3}$ Department of Non-communicable Chronic Disease Control and Prevention, Suzhou City Center for Disease Control and Prevention, Suzhou 215004, China. ${ }^{4}$ Wuzhong District of Suzhou City Center for Disease Control and Prevention, Suzhou 215100, China. ${ }^{5}$ Chinese Academy of Medical Sciences, Beijing 102308, China. ${ }^{6}$ Clinical Trial Service Unit \& Epidemiological Studies Unit (CTSU), Nuffield Department of Population Health, University of Oxford, Oxford OX3 7LF, UK. 'Department of Epidemiology and Biostatistics, School of Public Health, Peking University, Beijing 100191, China.

Received: 6 December 2020 Accepted: 1 March 202

Published online: 16 March 2021

References

1. Zhou B, Bentham J, Di Cesare M, Bixby H, Danaei G, Cowan MJ, Paciorek CJ, Singh G, Hajifathalian K, Bennett JE, et al. Worldwide trends in blood pressure from 1975 to 2015: a pooled analysis of 1479 population-based measurement studies with 19.1 million participants. Lancet. 2017;389(10064): $37-55$.

2. Wang Z, Chen Z, Zhang L, Wang X, Hao G, Zhang Z, Shao L, Tian Y, Dong Y, Zheng $C$, et al. Status of hypertension in China: results from the China hypertension survey, 2012-2015. Circulation. 2018;137(22):2344-56.

3. Lewington S, Lacey B, Clarke R, Guo Y, Kong XL, Yang L, Chen Y, Bian Z, Chen J, Meng J, et al. The burden of hypertension and associated risk for cardiovascular mortality in China. JAMA Intern Med. 2016;176(4):524-32.

4. Oparil S, Acelajado MC, Bakris GL, Berlowitz DR, Cifkova R, Dominiczak AF, Grassi G, Jordan J, Poulter NR, Rodgers A, et al. Hypertension. Nat Rev Dis Primers. 2018;4:18014.

5. Piercy KL, Troiano RP, Ballard RM, Carlson SA, Fulton JE, Galuska DA, George SM, Olson RD. The physical activity guidelines for Americans. JAMA. 2018; 320(19):2020-8.

6. Hamer M, Stamatakis E. Physical activity and risk of cardiovascular disease events: inflammatory and metabolic mechanisms. Med Sci Sports Exerc. 2009:41(6):1206-11.

7. Wu NN, Tian H, Chen P, Wang D, Ren J, Zhang Y. Physical exercise and selective autophagy: benefit and risk on cardiovascular health. Cells. 2019; 8(11):1436.

8. O'Donovan G, Lee IM, Hamer M, Stamatakis E. Association of "weekend warrior" and other leisure time physical activity patterns with risks for allcause, cardiovascular disease, and cancer mortality. JAMA Intern Med. 2017; 177(3):335-42.

9. Kraus WE, Powell KE, Haskell WL, Janz KF, Campbell WW, Jakicic JM, Troiano RP, Sprow K, Torres A, Piercy KL, et al. Physical activity, all-cause and cardiovascular mortality, and cardiovascular disease. Med Sci Sports Exerc. 2019;51(6):1270-81.

10. Williams B, Mancia G, Spiering W, Agabiti Rosei E, Azizi M, Burnier M, Clement DL, Coca A, de Simone G, Dominiczak A, et al. 2018 ESC/ESH guidelines for the management of arterial hypertension. Eur Heart J. 2018; 39(33):3021-104.

11. Joseph G, Marott JL, Torp-Pedersen C, Biering-Sorensen T, Nielsen G,

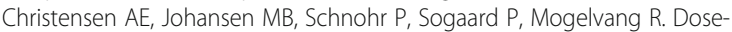
response association between level of physical activity and mortality in normal, elevated, and high blood pressure. Hypertension. 2019;74(6):130715.

12. Churilla JR, Ford ES. Comparing physical activity patterns of hypertensive and nonhypertensive US adults. Am J Hypertens. 2010;23(9):987-93.

13. Ma C. The evaluation of physical activity for community-dwelling patients with hypertension. J Clin Nurs. 2017;26(17-18):2712-20. 
14. Autenrieth CS, Baumert J, Baumeister SE, Fischer B, Peters A, Doring A, Thorand B. Association between domains of physical activity and all-cause, cardiovascular and cancer mortality. Eur J Epidemiol. 2011;26(2):91-9.

15. Matthews CE, Keadle SK, Troiano RP, Kahle L, Koster A, Brychta R, Van Domelen D, Caserotti P, Chen KY, Harris TB, et al. Accelerometer-measured dose-response for physical activity, sedentary time, and mortality in US adults. Am J Clin Nutr. 2016;104(5):1424-32.

16. Ng SW, Howard AG, Wang HJ, Su C, Zhang B. The physical activity transition among adults in China: 1991-2011. Obes Rev. 2014;15(Suppl 1):27-36.

17. Chen Z, Chen J, Collins R, Guo Y, Peto R, Wu F, Li L, China Kadoorie Biobank collaborative g. China Kadoorie Biobank of 0.5 million people: survey methods, baseline characteristics and long-term follow-up. Int J Epidemiol. 2011;40(6):1652-66.

18. Chen Z, Lee L, Chen J, Collins R, Wu F, Guo Y, Linksted P, Peto R. Cohort profile: the Kadoorie Study of Chronic Disease in China (KSCDC). Int J Epidemiol. 2005;34(6):1243-9.

19. Huang C, Chen G, Zhang M, Lu Y, Hua Y, Hu Y, Jin J, Zhou J, Bian Z, Guo Y, et al. Association between environmental tobacco smoke exposure and risk of type 2 diabetes mellitus in Chinese female never smokers: a populationbased cohort study. J Diabetes. 2020;12(4):339-46.

20. Huang CY, Li JX, Chen SF, Chen JC, Lu Y, Huang QL, Wang LC, Hua YJ, Hu $\mathrm{YH}$. Years of potential life lost due to premature death of cardiovascular diseases among residents in Suzhou from 1987 to 2017. Zhonghua Yu Fang Yi Xue Za Zhi. 2020;54(1):104-7.

21. Wareham NJ, Jakes RW, Rennie KL, Mitchell J, Hennings S, Day NE. Validity and repeatability of the EPIC-Norfolk Physical Activity Questionnaire. Int J Epidemiol. 2002;31(1):168-74.

22. Matthews CE, Shu XO, Yang G, Jin F, Ainsworth BE, Liu D, Gao YT, Zheng W. Reproducibility and validity of the Shanghai Women's Health Study physical activity questionnaire. Am J Epidemiol. 2003;158(11): 1114-22.

23. Zhu N, Yu C, Guo Y, Bian Z, Han Y, Yang L, Chen Y, Du H, Li H, Liu F, et al. Adherence to a healthy lifestyle and all-cause and cause-specific mortality in Chinese adults: a 10-year prospective study of 0.5 million people. Int J Behav Nutr Phys Act. 2019;16(1):98.

24. Ainsworth BE, Haskell WL, Herrmann SD, Meckes N, Bassett DR Jr, TudorLocke C, Greer JL, Vezina J, Whitt-Glover MC, Leon AS. 2011 Compendium of Physical Activities: a second update of codes and MET values. Med Sci Sports Exerc. 2011;43(8):1575-81.

25. Joint Committee for Guideline R. 2018 Chinese guidelines for prevention and treatment of hypertension-a report of the revision Committee of Chinese Guidelines for prevention and treatment of hypertension. J Geriatr Cardiol. 2019;16(3):182-241.

26. Pang Y, Holmes MV, Guo Y, Yang L, Bian Z, Chen Y, lona A, Millwood IY, Bragg F, Chen J, et al. Smoking, alcohol, and diet in relation to risk of pancreatic cancer in China: a prospective study of 0.5 million people. Cancer Med. 2018;7(1):229-39.

27. Millwood IY, Li L, Smith M, Guo Y, Yang L, Bian Z, Lewington S, Whitlock G, Sherliker P, Collins R, et al. Alcohol consumption in 0.5 million people from 10 diverse regions of China: prevalence, patterns and socio-demographic and health-related correlates. Int J Epidemiol. 2013;42(3):816-27.

28. Wang M, Gong WW, Hu RY, Pan J, Lv J, Guo Y, Bian Z, Chen ZM, Li LM, Zhong JM. Associations between stressful life events and diabetes: findings from the China Kadoorie Biobank study of 500,000 adults. J Diabetes Investig. 2019;10(5):1215-22.

29. American Diabetes A. Diagnosis and classification of diabetes mellitus Diabetes Care. 2013;36(Suppl 1):S67-74.

30. Mora S, Cook N, Buring JE, Ridker PM, Lee IM. Physical activity and reduced risk of cardiovascular events: potential mediating mechanisms. Circulation. 2007;116(19):2110-8.

31. Fan M, Yu C, Guo Y, Bian Z, Li X, Yang L, Chen Y, Li M, Li X, Chen J, et al. Effect of total, domain-specific, and intensity-specific physical activity on allcause and cardiovascular mortality among hypertensive adults in China. J Hypertens. 2018:36(4):793-800.

32. Organization $\mathrm{WH}$. WHO guidelines on physical activity and sedentary behaviour. Geneva: World Health Organization; 2020.

33. Borjesson $\mathrm{M}$, Onerup $\mathrm{A}$, Lundqvist $\mathrm{S}$, Dahlof $\mathrm{B}$. Physical activity and exercise lower blood pressure in individuals with hypertension: narrative review of 27 RCTs. Br J Sports Med. 2016:50(6):356-61.
34. Hu G, Jousilahti P, Antikainen R, Tuomilehto J. Occupational, commuting, and leisure-time physical activity in relation to cardiovascular mortality among finnish subjects with hypertension. Am J Hypertens. 2007;20(12): 1242-50.

35. Kubota Y, Iso H, Yamagishi K, Sawada N, Tsugane S, Group JS. Daily Total physical activity and incident stroke: the Japan public health center-based prospective study. Stroke. 2017;48(7):1730-6.

36. Weiss SA, Blumenthal RS, Sharrett AR, Redberg RF, Mora S. Exercise blood pressure and future cardiovascular death in asymptomatic individuals. Circulation. 2010;121(19):2109-16.

37. Radak Z, Chung HY, Koltai E, Taylor AW, Goto S. Exercise, oxidative stress and hormesis. Ageing Res Rev. 2008;7(1):34-42.

38. Kyu HH, Bachman VF, Alexander LT, Mumford JE, Afshin A, Estep K, Veerman $J$, Delwiche K, lannarone ML, Moyer ML, et al. Physical activity and risk of breast cancer, colon cancer, diabetes, ischemic heart disease, and ischemic stroke events: systematic review and dose-response meta-analysis for the Global Burden of Disease Study 2013. BMJ. 2016;354:13857.

39. Wahid A, Manek N, Nichols M, Kelly P, Foster C, Webster P, Kaur A, Friedemann Smith C, Wilkins E, Rayner M, et al. Quantifying the association between physical activity and cardiovascular disease and diabetes: a systematic review and meta-analysis. J Am Heart Assoc. 2016;5(9):e002495.

40. Sharman JE, La Gerche A, Coombes JS. Exercise and cardiovascular risk in patients with hypertension. Am J Hypertens. 2015;28(2):147-58.

41. Seals DR, Desouza CA, Donato AJ, Tanaka H. Habitual exercise and arterial aging. J Appl Physiol (1985). 2008;105(4):1323-32.

42. Stewart LK, Flynn MG, Campbell WW, Craig BA, Robinson JP, Timmerman KL, McFarlin BK, Coen PM, Talbert E. The influence of exercise training on inflammatory cytokines and C-reactive protein. Med Sci Sports Exerc. 2007; 39(10):1714-9.

43. Wisloff $U$, Ellingsen $O$, Kemi OJ. High-intensity interval training to maximize cardiac benefits of exercise training? Exerc Sport Sci Rev. 2009;37(3):139-46.

44. Gioscia-Ryan RA, Battson ML, Cuevas LM, Zigler MC, Sindler AL, Seals DR. Voluntary aerobic exercise increases arterial resilience and mitochondrial health with aging in mice. Aging (Albany NY). 2016;8(11):2897-914.

\section{Publisher's Note}

Springer Nature remains neutral with regard to jurisdictional claims in published maps and institutional affiliations.

Ready to submit your research? Choose BMC and benefit from:

- fast, convenient online submission

- thorough peer review by experienced researchers in your field

- rapid publication on acceptance

- support for research data, including large and complex data types

- gold Open Access which fosters wider collaboration and increased citations

- maximum visibility for your research: over $100 \mathrm{M}$ website views per year

At $\mathrm{BMC}$, research is always in progress.

Learn more biomedcentral.com/submissions 